\title{
THORAX
}

Editorials

\section{New insights into the pathogenesis of interstitial pulmonary fibrosis}

The interstitial lung diseases are a heterogeneous group of disorders characterised by diffuse and often progressive lung parenchymal inflammation and fibrosis which can result in severe impairment of respiratory function and eventual respiratory failure. ${ }^{12}$ Although many aetiological factors of interstitial lung fibrosis have been identified, in many instances the cause of these disorders remains unknown. Regardless of the causative agent, however, a common pathological feature is the thickening of the alveolar septum with considerable accumulation of fibrotic tissue $^{3}$ and variable degrees of inflammatory cell infiltration and alveolar collapse. The importance of the inflammatory component in interstitial lung diseases has been emphasised by Crystal et $a l^{4}$ and it has been suggested that alveolar inflammation secondary to various endogenous and exogenous stimuli may initiate the fibrotic process. ${ }^{5}$ Despite intensive recent investigations on various aspects of the interstitial pulmonary diseases in $\operatorname{man}^{67}$ and the study of several animal models that mimic certain features of the human disease, ${ }^{8}$ the mechanisms responsible for the excessive accumulation of fibrous tissue in the alveolar walls have not been completely elucidated. Furthermore, it is not known at present if the development of alveolar fibrosis in all forms of interstitial lung disease, including idiopathic pulmonary fibrosis, is the result of a common pathological event.

Normal fibroblasts are capable of regulating collagen production according to the dynamic requirements of the extracellular matrix during development, differentiation, and repair. ${ }^{9-12}$ There are three general mechanisms by which the production of these macromolecules can be controlled: (1) transcriptional regulation of collagen gene expression; (2) control of mRNA translation; and (3) variation in the fraction of the newly synthesised collagen which is degraded before it is secreted out of the cell. Although it is well recognised that modulation of the rates of translation of mature RNA collagen transcripts, as well as regulation of the intracellular degradation of newly synthesised collagen, may have important roles in determining the net amount of collagen produced by a given cell, we have recently shown that transcriptional regulation of procollagen genes is the most important mechanism (Diaz and Jimenez, unpublished observations).

The upstream elements of the type I procollagen genes (COL1A1 and COL2A2) are principal targets for the action of promoter-specific transcription factors. ${ }^{9-12}$ These factors may affect the initiation of the transcription complex itself. Alternatively, transcription factors may act by several mechanisms further upstream of the initiation complex and may exert either stimulatory or inhibitory influences on the rate of transcription of these genes.
Indeed, both stimulatory and inhibitory DNA binding proteins that modulate specifically collagen gene transcription have been described and characterised. ${ }^{13-16}$ Transcription factors may also bind to enhancer elements within the first intron of these genes to bring about transcriptional regulation. ${ }^{17-19}$ The studies of the effects of transcriptional/DNA binding factors on the collagen gene promoter regions indicate that the mechanisms involved are very complex and undoubtedly influence the tissue specificity and the levels of procollagen gene expression in response to internal and/or external perturbations.

In addition to DNA binding factors that interact with promoter and enhancer elements within the collagen genes, other mechanisms may account for alterations in transcriptional regulation; these include the structure of the chromatin surrounding gene promoter regions and the levels of methylation of the upstream regulatory regions of the genes. The upstream sequences of actively transcribed genes often contain regions of DNAse I hypersensitivity which may represent nucleosome-free regions that can interact with various regulatory proteins, thus controlling the level of expression of a given gene. Indeed, discrete chromatin domains have been identified in the chromatin surrounding the mouse $\alpha_{1}(\mathrm{I})$ procollagen gene promoter. ${ }^{20}$ Furthermore, an examination of the methylation pattern of the human COL1Al suggested that DNA methylation may be an important mechanism of transcriptional inactivation of interstitial collagen genes. ${ }^{21}$

Despite the recent advances in the understanding of the regulation of transcription of the genes encoding interstitial collagens under physiological conditions, very little has been learned regarding the intimate mechanisms responsible for the pathological increase in their expression in fibrotic diseases in general, or in idiopathic pulmonary fibrosis in particular. The possibility that a viral agent may be the cause of some diseases that are accompanied by tissue inflammation and fibrosis, such as certain autoimmune diseases, has long been suspected. ${ }^{22}{ }^{23}$ It is considered that approximately $5 \%$ of the human genome is of viral origin that has been integrated through reverse transcription. These viral sequences can eventually become expressed and lead to the production of viral proteins which, in turn, may influence the expression of host cellular genes by disruption of their structure or by regulation of their transcription. For example, it has been shown that two proteins encoded in the genomes of the slow retrovirus HIV-I and the oncovirus HTLV-I, known as Tat and Tax respectively, may affect the expression of several cellular genes. HTLV-I Tax induces the expression of IL-2, ${ }^{24}$ IL-2 receptor, ${ }^{24}{ }^{25}$ granulocyte-macrophage colony stimulating factor, IL-1, IL-6, platelet derived growth factor $\beta$, transforming growth factor (TGF- $\beta$ ), ${ }^{2627}$ 
and interferon $\gamma{ }^{28}$ On the other hand, HIV-I Tat is able to induce the expression of tumour necrosis factor $\alpha^{29}$ and TGF $-\beta_{1}{ }^{30}$

The effects of the retroviral proteins on the expression of important cytokines that are involved in the regulation of various immune functions, as well as in the modulation of expression of genes encoding extracellular matrix proteins, provide a possible mechanism for the participation of retroviruses in the pathogenesis of lung fibrosis. The induction of TGF- $\beta$ by Tat provides a link between retroviral infection and our recent findings of in vitro activation of expression of collagen and fibronectin genes by $\mathrm{Tat}^{31}$ and $\operatorname{Tax}^{32}$ The potential of retroviruses to alter the expression of extracellular matrix protein genes has also been shown in vivo as indicated by the development of glomerulosclerosis in mice transgenic for a non-infectious form of HIV-I. ${ }^{33}$ The mechanisms responsible for the stimulation of expression of the genes encoding extracellular matrix proteins by Tat or Tax are not known. The promoters of these genes contain sequences that are recognised by numerous transcriptional factors. It is possible that Tat or Tax proteins trans-activate these genes through stimulation of the activity of trans-acting DNA binding regulatory proteins that recognise sequences at any of these sites. It is also likely that indirect pathways may be involved - for example, through the induction of genes that increase the expression of extracellular matrix proteins such as TGF- $\beta$.

It is therefore becoming apparent that stimulation of the expression of genes encoding extracellular matrix proteins by products of viral genes may represent a potentially important mechanism in the pathogenesis of fibrotic diseases including idiopathic pulmonary fibrosis. In a very elegant study reported in this issue of Thorax Matsui and coworkers $^{34}$ investigated the regulation of collagen gene expression in cultures of neonatal type II alveolar cells immortalised by retroviral mediated transfer of the adenoviral Ad12SE1A gene. Their results indicate that 12SE1A gene transfer causes the production of large amounts of type I collagen with a predominance of $\alpha_{1}(\mathrm{I})$ trimer molecules by the immortalised type II cells. These studies are very important on several accounts. Firstly, they provide evidence that type II alveolar cells, which are known to produce several types of extracellular matrix proteins, including the basement membrane component type IV collagen, but which are not capable of production of the interstitial type I collagen, under certain circumstances may be induced to change their biosynthetic programme and may initiate the synthesis of mesenchymal cell specific proteins. Secondly, these studies show that, although expression of viral proteins in mesenchymal cells almost invariably causes a marked inhibition of type I collagen production, certain viral products such as those encoded by the adenovirus gene $12 \mathrm{SE} 1 \mathrm{~A}$ may result in increased production of type I collagen. Furthermore, these effects appear to be exerted at the transcriptional level and to be mediated by specific sequences within the promoter of the genes encoding type I collagen. Thirdly, the evidence presented by Matsui et al also indicates that the extracellular matrix produced by the immortalised alveolar type II cells containing almost exclusively $\alpha_{1}(\mathrm{I})$ trimer collagen molecules may have an abnormal structure that is distinct from that produced by normal mesenchymal cells. The matrix enriched for $\alpha_{1}(I)$ trimers may have peculiar properties regarding important processes such as collagen degradation, cell adhesion, and migration.

The studies of Matsui et al therefore provide additional support to a growing body of evidence indicating that the expression of proteins encoded by nucleotide sequences of viral origin in mesenchymal and epithelial cells could result in their activation regarding extracellular matrix production. Thus, a working hypothesis to explain the pathogenesis of idiopathic pulmonary fibrosis and other fibrotic lung diseases is emerging. This hypothesis postulates that the expression of viral genes could enhance the promoter activity of genes that play a crucial role in the initiation and/or progression of tissue fibrosis such as those encoding extracellular matrix proteins, cytokines and growth factors, and their receptors. Furthermore, expression of viral genes may result in molecular changes in $T$ cells, macrophages or endothelial cells, such as aberrant oncogene expression, ${ }^{35}{ }^{36}$ induction of immediate early genes, ${ }^{37}$ and alterations in the patterns of integrins and cell adhesion proteins expressed in their surfaces. A cascade of secondary effects may then be triggered resulting in the excessive connective tissue production and cellular immune dysfunction characteristic of idiopathic pulmonary fibrosis and other fibrosing diseases affecting the lungs. Of relevance to this concept are the recent descriptions of the occurrence of severe pulmonary hypertension associated with perivascular fibrosis in pulmonary vessels in some patients with HIV infection, ${ }^{38}$ and of the presence in sera from certain patients with scleroderma (a disease that frequently causes pulmonary fibrosis) of antibodies to the $24^{\text {gag }}$ nucleocapside protein of HIV-I. ${ }^{39}$ The observations of Matsui et al strongly support the hypothesis that expression of viral proteins may be involved in the development of certain forms of interstitial lung fibrosis in humans.

Thomas fefferson University,

Bluemle Life Sciences Building,

SERGIO A JIMENEZ

233 South 10th Street,

Philadelphia,

Pennsylvania 19107-5541,

USA

1 Phan SH. Diffuse interstitial fibrosis. In: Massaro D, ed. Lung cell biology. New York: Marcel Dekker, 1989:907-80.

2 Crouch E. Pathobiology of pulmonary fibrosis. Am $f$ Physio 1990;259:L159-84.

3 Raghu G, Striker LJ, Hudson LD, Striker GE. Extracellular matrix in normal and fibrotic lungs. Am Rev Respir Dis 1985;131:281-9.

4 Crystal RG, Bitterman PB, Rennard SI, Hance AJ, Keogh BA. Intersticial lung diseases of unknown cause. $N$ Engl $\mathcal{F}$ Med 1984;310:154-66.

5 Sheppard MN, Harrison NK. Lung injury, inflammatory mediators and fibroblast activation in fibrosing alveolitis. Thorax 1992;47:1064-74

6 DuBois RM. Recent advances in the immunology of interstitial lung disease. Clin Exp Allergy 1991;21:9-16.

$7 \mathrm{McDonald}$ JA. Idiopathic pulmonary fibrosis. A paradigm of lung injury and repair. Chest 1991;99:875-93.

8 Richards RJ, Masek LC, Brown RF. Biochemical and cellular mechanisms of pulmonary fibrosis. Toxicol Pathol 1991;19:526-39.

9 Bornstein P, Sage H. Regulation of collagen gene expression. Prog Nucleic Acids Res 1989;37:67-106.

10 Adams SL. Collagen gene expression. Am f Respir Cell Mol Biol 1989;1:161-8.

11 Ramirez F, DiLiberto $M$. Complex and diversified regulatory programs control the expression of vertebrate collagen genes. FASEB $f$ 1990;4:1616-23.

12 Boast S, Su MW, Ramirez F, Sanchez M, Avvedimento EV. Functional analysis of cis-acting DNA sequences controlling transcription of human analysis of cis-acting DNA sequences controlling transcip

13 Rossi P, Karsenty G, Roberts AB, Roche NS, Sporn MB, de Crombrugghe B. A nuclear factor 1 binding site mediates the transcriptional activation of a type I collagen promoter by transforming growth factor $-\beta$. Cell 1988;52:405-14

14 Karsenty G, de Crombrugghe B. Two different negative and one positive regulatory factors interact with a short promoter segment of the $\alpha 1(I)$ collagen gene. I Biol Chem 1990;265:9934-42.

15 Simkevich CP, Thompson JP, Poppleton H, Raghow R. The transcriptional tissue specificity of the human pro- $\alpha 1(\mathrm{I})$ collagen gene is determined by a negative cis-regulatory element in the promoter. Biochem $f$ 1992;286:179-85.

16 Maity SN, de Crombrugghe B. Biochemical analysis of the subunit of the heteromeric CCAAT-binding factor. I Biol Chem 1992;267:8286-92.

17 Rossouw CMS, Vegeer WP, du Plooy SJ, Bernard MP, Ramirez F, de Wet WJ. DNA sequences in the first intron of the human pro- $\alpha 1$ (I) collagen gene enhance transcription. $\mathcal{F}$ Biol Chem 1987;262:15151-7.

18 Bornstein P, McKay J, Morishima JK, Devarayalu S, Gelinas RE. Regulatory elements in the first intron contribute to transcriptional control of the human $\alpha 1$ (I) collagen gene. Proc Natl Acad Sci USA 1987;84:886973.

19 Borstein P, McKay J. The first intron of the $\alpha 1(\mathrm{I})$ collagen gene contains several transcriptional regulatory elements. $\mathcal{F}$ Biol Chem 1988;263:1603-6.

20 Liau G, Szapary D, Setoyama C, de Crombrugghe B. Restriction enzyme digestions identify discrete domains in the chromatin around the promoter of the mouse $\alpha 2(\mathrm{I})$ collagen gene. $¥$ Biol Chem 1986;261:11362-8.
moling 
21 Thompson JP, Simkevich CP, Holness MA, Kang AH, Raghow R. In vitro methylation of the promoter and enhancer of pro- $\alpha 1(\mathrm{I})$ collagen gen leads to its transcriptional inactivation. F Biol Chem 1991;266:2549-56.

$22 \mathrm{Krieg}$ AM, Steinberg AD. Retroviruses and autoimmunity. $\mathcal{F}$ Autoimmunity 1990;3:137-66.

23 Schattner A, Rager-Zisman B. Virus-induced autoimmunity. Rev Infect Dis 1990;12:204-22.

24 Siekevitz M, Feinberg MB, Holbrook N, Wong-Staal F, Greene WC. Activation of interleukin-2 and interleukin-2 receptor (Tac) promoter expression by the transactivator (Tat) gene product of human T-cell expression by the transactivator (Tat) gene product of human
leukemia virus, type I. Proc Natl Acad Sci USA 1987;84:5389-93.

25 Leung K, Nabel GJ. HTLV-I transactivator induces interleukin-2 receptor expression through an NF-kB-like factor. Nature 1988;333:776-8.

26 Shinohara T. HTLV-I Tax mediated activation of cellular genes in transgenic mice. Hokkaido $\mathcal{f}$ Med Sci 1991;66:534-43.

27 Sawada M, Suzumura A, Kondo N, Marunuouchi T. Induction of cytokines in glial cells by trans-activator of human $\mathrm{T}$ cell lymphotropic virus type I. FEBS Lett 1992;313:47-50.

28 Brown DA, Nelson FB, Reinberg EL, Diamond DJ. The human interferon- $\gamma$ gene contains an inducible promoter that can be transactivated by Tax I and II. Eur f Immunol 1991;21:1879-85.

29 Bounaguro L, Barillari G, Chang HK, Bohan CA, Kao V, Morgan R, et al. Effects of the human immunodeficiency virus type I Tat protein on the expression of inflammatory cytokines. $\mathcal{F}$ Virol 1992;66:7159-67.

30 Cupp C, Taylor JP, Khalili K, Amini S. Evidence for stimulation of the transforming growth factor- $\beta_{1}$ promoter by HIV-I Tat in cells derived transforming growth factor- $\beta_{1}$ prom
from CNS. Oncogene 1993;8:2231-6.

31 Taylor JP, Cupp C, Diaz A, Chowdhury M, Khalili K, Jimenez SA, et al.
Activation of expression of genes coding for extracellular matrix proteins in Tat-producing glioblastoma cells. Proc Natl Acad Sci USA 1992;89:9617-21.

32 Munoz E, Khalili K, Amini S, Jimenez SA. Stimulation of the expression of genes encoding matrix proteins by the HTLV-I transregulatory protein Tax. Arthritis Rheum 1992;35(Suppl):S38.

33 Kopp JB, Klotman ME, Adler SH, Bruggeman LA, Dickie P, Marinos NJ, et al. Progressive glomerulosclerosis and enhanced renal accumulation of basement membrane components in mice transgenic for human immunodeficiency virus type I genes. Proc Natl Acad Sci USA 1992;89:1577-81.

34 Matsui R, Goldstein RH, Mihal K, Brody JS, Steele MP, Fine A. Type I collagen formation in rat type II alveolar cells immortalised by viral gene products. Thorax 1994;49:201-6.

35 Alexandre C, Verrier B. Four regulatory elements in the human c-fos promoter mediate transactivation by HTLV-I Tax protein. Oncogene 1991;6:543-51

36 Duyao MP, Kessler DJ, Spicer DB, Sonenshein GE. Transactivation of the murine C-myc gene by HTLV-I Tax is mediated by NF-kB. AIDS Res Hum Retrovir 1992;8:752-4.

37 Fujii M, Niki T, Mori T, Matsuda T, Matsui M, Nomura N, et al. HTLVI Tax induces expression of various immediate early serum responsive genes. Oncogene 1991;6:1023-9.

38 Coplan NL, Shimony RY, Ioachim Hl, Wilentz JR, Posner DH, Lipschitz $A$, et al. Primary pulmonary hypertension associated with human immunodeficiency viral infection. Am $f$ Med 1990;89:96-9.

39 Dang H, Dauphinee MJ, Talal N, Garry RF, Seibold JR, Medsger TA, et al. Serum antibody to retroviral gag proteins in systemic sclerosis. al. Serum antibody to retroviral
Arthritis Rheum 1991;34:1336-7. 